\title{
Academic events as interfaces between the Stricto Sensu Postgraduation and Basic Education
}

\section{Tiago M. A. Salviano, Taina R. Gomes*, Leonardo Granero, Joyce Wassem}

\begin{abstract}
This research analyses the interfaces of 45 Postgraduate Programs (in Portuguese, PPG) of the State University of Campinas (UNICAMP) with basic education. Data collection was carried out through the content analysis of each program's evaluation sheet, made available in the Sucupira Platform by the Coordination for Improvement of Higher Education Personnel (in Portuguese, CAPES), for the year 2017. From the data collection, ten categories were listed and, for the purposes of this study, the category "Academic Events" was selected for further study, indicated by $54.3 \%$ of PPGs studied as an interface activity with Basic Education. Among the events mentioned by the PPG are: UNICAMP Open Doors (in Portuguese, UPA), Science \& Holiday Arts (in Portuguese, CAF) and the Institute of Arts' Student Festival (in Portuguese, FEIA), aimed at students of basic education, mainly high school and community in general, with the purpose of presenting the institutional space of UNICAMP, its teaching, research and extension activities, allowing greater interaction between the internal and the external communities.
\end{abstract}

\section{Key words: Stricto Sensu Postgraduate Programs, Basic Education, Academic Events.}

\section{Introduction}

The National Postgraduate Plans (in Portuguese, PNPG) deliberate on the policies that will be implemented within the scope of the Brazilian National Graduate System (in Portuguese, SNPG), as well as in the evaluation of PPG undertaken by CAPES. The VI PNPG (2011-2020) is into force. This plan contemplates basic education as a strategic point for the stricto sensu postgraduate with emphasis on the support to basic education, as well as other levels and modalities of education, especially the high school, not being restricted to the PPG from the area of Education'. In this context, CAPES evaluation incorporated the item "Interfaces with basic education" from 2013 on, in the Social Inclusion section. This research had as objective to analyse the interfaces of PPG of UNICAMP with basic education.

\section{Results and Discussion}

Data collection was performed through content analysis ${ }^{2}$ of the item "Interfaces with Basic Education", present in the 2017 evaluation form of each PPG, provided by CAPES. From the data collection ten categories were listed and, for the purposes of this study, the category "Academic Events" was selected for further study. The events with the highest incidence of registrations in the PPGs studied were: UPA, CAF and FEIA. UPA is an annual event, aimed mainly at basic education students from all over the country, especially students from high school. The event is organized predominantly by undergraduate and graduate students, with the purpose of promoting a day of interaction between students of basic education and the University, presenting the institutional spaces, as well as the actions developed in the areas of research, teaching and extension. From 2018, UPA began to be held in the first semester, enabling students to know the courses and the institution before enrolling in the college entrance examination. $\mathrm{CAF}$, which takes place annually in January and counts on the participation of students from high school of public schools in the region of Campinas, Limeira and Piracicaba, is promoted by the Pro-Rectory of Research of UNICAMP, being supervised by professors and researchers from UNICAMP. In 2017, in the 15th edition,
CAF had 406 enrolled students, of which 220 were selected from among the 72 participating schools. UNICAMP had 108 supervisors, in a total of 108 projects/workshops offered: 32 in the area of biological sciences, 7 in exact sciences, 11 in human sciences/arts and 58 in technological sciences. FEIA, currently in its 20th edition (2019), is an event of diffusion of the arts, considered relevant in the cultural directory of Campinas, free and open to the public. It was created from the initiative of students from several courses of UNICAMP, has the rotation of the team that organizes it and annually offers workshops, presentations of music, dance, theatre; conversation circles, among others, for the university's internal and external population.

\section{Conclusions}

It is possible to infer, from the data, that the events mentioned by the PPG, especially UPA and CAF, as interface actions with Basic Education, are institutionalized by UNICAMP, from which PPG, its professors and students can participate, but are not necessarily institutional projects of the programs, which does not impair their contribution and interaction with basic education and the external community, bringing it closer to the university reality.

\section{Acknowledgement}

To the Student Support Service - Serviço de Apoio ao Estudante (SAE) of UNICAMP, for the concession of the Social Assistance Scholarship - Bolsa Auxílio Social (BAS) to the scientific project that supports this research.

\footnotetext{
${ }^{1}$ BRASIL. Ministério da Educação. Plano Nacional de Pós-Graduação 2011 2020. Brasília, DF: MEC/CAPES, 2010.

2 MORAES, Roque. Análise de conteúdo. Revista Educação. Porto Alegre, v. 22 , n. 37 , p. 7-32, 1999
} 